\title{
La financiación de los partidos políticos en España. Consideraciones a partir de los informes del Tribunal de Cuentas y de la nueva Ley Orgánica 8/2007, de 4 de julio
}

\section{Joan Lluís Pérez Francesch}

Universitat Autònoma de Barcelona. Departament de Ciència Política i Dret Públic 08193 Bellaterra (Barcelona). Spain joanlluis.perez.francesch@uab.cat

\section{Resumen}

Se analiza la nueva Ley Orgánica de financiación de los partidos políticos (LO 8/2007, de 4 de julio) y algunos informes del Tribunal de Cuentas relativos a la fiscalización de la contabilidad de los partidos políticos —en especial, los últimos publicados relativos a los ejercicios de 2003, 2004 y 2005. Se destacan los problemas que en aquella sede se han puesto de manifiesto en relación con la financiación de los partidos políticos, las propuestas de la nueva ley y la exigencia de llevar a cabo un control exhaustivo de los estados contables de los partidos políticos, como paradigma del Estado democrático.

Palabras clave: partidos políticos, política, financiación, fiscalización, contabilidad, democracia.

Abstract. The financing of political parties in Spain. About Auditing Court Reports and the new organic Act 8/2007, of the 4 th. of july

This article analyzes the new organic Act about financing of political parties (LO 8/2007, of the $4^{\text {th }}$ of July) and several Auditing Court reports regarding the auditing of the political parties accountancy — specially those last published, regarding the 2003, 2004 and 2005 fiscal year. The problems that the Auditing court exposed regarding the political parties accountancy, the proposals of the new organic Act and the demands to implement a thorough control over the financial statements of the political parties, as paradigm of the democratic State, should be highlighted.

Key words: political parties, polítics, financing, auditing, accountancy, democracy.

\section{Sumario}

\section{Introducción 3. Aspectos destacables de la nueva ley}

2. La nueva ley, entre los problemas de financiación tradicionales y algunos puntos que se pretenden mejorar

4. Consideraciones finales

5. Referencias bibliográficas

6. Anexos 


\section{Introducción}

En las líneas que siguen, nos proponemos analizar la nueva regulación operada por la Ley Orgánica de financiación de los partidos políticos (LO 8/2007, de 4 de julio). Asimismo, hemos consultado algunos informes del Tribunal de Cuentas relativos a la fiscalización de la contabilidad de los partidos políticos - el último publicado es el relativo al ejercicio de 2005-, para poder comprender mejor los problemas que en aquella sede se han puesto de manifiesto en relación con la financiación de los partidos y a los estados contables de los mismos.

El propio Tribunal de Cuentas había solicitado reiteradamente la reforma de la Ley como una de sus recomendaciones más recurrentes e, incluso, el 30 de octubre de 2001, aprobó una moción en este sentido (Tribunal de Cuentas, 2001). También la Comisión Mixta Congreso-Senado de relaciones con el Tribunal de Cuentas había requerido reiteradamente dicha reforma.

Ahora habrá que ver la aplicación de los criterios y la capacidad de adaptación de los partidos a los requerimientos de la nueva ley y del propio Tribunal de Cuentas. Hay que tener en cuenta que los informes se dan a conocer a las Cortes Generales, en especial a la Comisión Mixta de Relaciones con el Tribunal de Cuentas, con cierto retraso, especialmente los referidos a los estados contables de las formaciones con representación parlamentaria. Por ello, deberemos esperar un cierto tiempo para analizar las consecuencias prácticas de la nueva ley.

La importancia del tema a tratar no necesita mucho desarrollo. Es un lugar común la consideración de los partidos políticos como elementos fundamentales del moderno Estado democrático y de lo que se ha venido en llamar la democracia de partidos. Así se deriva sin ir más lejos de lo dispuesto en el art. 6 $\mathrm{CE}$. Ahora bien, también es cierto que se han dado casos de corrupción o de financiación irregular, así como actuaciones desmesuradas, que han puesto de manifiesto deficiencias graves del estado de partidos. Asimismo, la omnipresencia de éstos en la esfera pública o, en ocasiones, su actuación excluyente de otras organizaciones sociales, ha permitido hablar de un «secuestro de la democracia», diferenciándose entre ésta última y la "partitocracia». También se plantea frecuentemente la conveniencia de una financiación adecuada de los partidos políticos con el debate de si ésta ha de ser pública o no, y en qué proporciones.

Por otro lado, el Barómetro global de la corrupción 2007, elaborado por la ONG Transparency International ${ }^{1}$, concluye que los partidos políticos son la institución más corrupta, según la opinión de la ciudadanía española, con una valoración de 3,9 sobre un máximo de 5, lo cual representa un $62 \%$ de los encuestados. En concreto, la financiación de los partidos es la principal sospecha de corrupción para los españoles.

1. http://www.transparency.org/news_room/in_focus/2007/gcb_2007. 


\section{La nueva ley, entre los problemas de financiación tradicionales $\mathrm{y}$ algunos puntos que se pretenden mejorar}

En este contexto, hemos de hacer referencia a la nueva Ley Orgánica de financiación de los partidos políticos, que sustituye a la LO 3/1987, de 2 de julio, y sus reformas posteriores ${ }^{2}$. La LO 8/2007, de 4 de julio, tiene su origen en la proposición de ley que ERC presentó en el Congreso de los Diputados el 20 de noviembre de 2005. En ella, la financiación se preveía de dos tipos: las aportaciones públicas para su funcionamiento ordinario, en los procesos electorales y sus grupos parlamentarios, y las donaciones privadas, siempre de personas físicas (no empresas), que no podían ser anónimas y exceder, en principio, de 30.000 euros al año por un mismo contribuyente, con posibilidad de desgravar. La prohibición de donaciones anónimas impidió avanzar con la reforma, puesto que PSOE, IU-ICV y ERC no querían mantenerlas, mientras que PP, CiU y el PNV, sí. A pesar de que, finalmente, se aceptó su supresión, la diferencia de criterios en este punto hizo que la ponencia no se creara hasta después de un año. Tras las elecciones autonómicas catalanas de 2006, el PSOE se comprometió con ERC a avanzar en el debate de la ley, y así se hizo hasta su aprobación y publicación en julio de 2007. Las enmiendas de ERC complementaban la proposición de ley exigiendo una regulación de las operaciones de condonación de deuda, mientras que el PSOE priorizaba su preferencia en que la labor fiscalizadora del Tribunal de Cuentas se extendiera a las fundaciones vinculadas a los partidos políticos y a impedir subvenciones a las formaciones que se encontraran en el entorno de las actividades terroristas relacionadas con las causas de ilegalización de los partidos según la ley reguladora de los mismos.

El PP, que presentó más de veinte enmiendas parciales, confirmó al final su voto favorable a la supresión de las donaciones anónimas; sus preocupaciones fueron la incorporación de las subvenciones en especie y la prohibición de la condonación de deudas a los partidos que las superaran en más de 90.000 euros anuales. Por su parte, $\mathrm{CiU}$, que se resistía a suprimir las donaciones anónimas, defendió la donación de personas jurídicas. Los nacionalistas vascos, catalanes y gallegos sostuvieron la elevación del máximo que una persona puede aportar a un partido político en 60.000 euros (PNV), 100.000 (CiU), 150.000 (BNG). El PNV defendió una enmienda curiosa en la que sostenía que los artículos de opinión, las informaciones y los editoriales de los medios de comunicación que beneficiasen el interés electoral de un partido fuesen considerados «donaciones en especie» y controlables por el Tribunal de Cuentas.

La nueva ley se aprueba finalmente con el voto en contra del PP - a mi juicio, más estratégico que otra cosa-, que no participa del consenso mayoritario final de los otros grupos. Los argumentos de oposición son: excesiva carga al erario público; falta de rigidez en el proceso de retirada de subvencio-

2. Procedimiento de elaboración de la ley en http://turan.uc3m.es/uc3m/dpto/PU/dppu02/ nov1.htm. 
nes a los partidos que son ilegalizados, y que se abre la puerta al perdón de las deudas y no prohíbe la donación de constructores y promotores (sic).

Una valoración global de la nueva ley ha de tener en cuenta el hecho de que como son los propios partidos, para entendernos, los que la aprueban, puede afirmarse que, en términos generales, éstos no aprobarán nunca una regulación negativa o improcedente para ellos mismos. Este elemento «autorreferencial» habrá que tenerlo en cuenta en las consideraciones que se hagan en relación con la financiación de los partidos (por ejemplo, la nueva ley prohíbe las donaciones anónimas, a cambio de un aumento suculento de la cantidad de dinero público de subvención directa que recibirán). En efecto, la nueva ley aumenta de 65 a 78 millones de euros, un 20\%, la subvención que, para el funcionamiento ordinario, reciben de los presupuestos generales del Estado. Además, autoriza a las comunidades autónomas, territorios históricos vascos y corporaciones locales a otorgar ayudas para el gasto ordinario de los partidos sin prefijar un límite. Al suprimirse las donaciones anónimas, mecanismo de importante financiación de algún partido nacionalista y aspecto atacado furibundamente por ERC, para atraerlos al consenso, y a la presunción de mayor limpieza en el origen de algunos recursos, se produce un aumento importante de la cantidad de dinero público que todos recibirán proporcionalmente. Si bien la exposición de motivos de la Ley habla de garantizar la suficiencia de los recursos y de asegurar su independencia, en realidad, son grandes palabras que, más allá de la retórica, plantean el problema de su cuantificación y de la percepción que tienen los ciudadanos del sistema de financiación en el marco del proceso de descrédito de la política. En efecto, el dato de que los destinatarios de las subvenciones son los mismos que aquéllos que las aprueban realmente, es un elemento sustancialmente diferente del resto de las subvenciones públicas, con la consiguiente desconfianza que esto provoca en los ciudadanos, concebidos aquí también como contribuyentes. Uno de los problemas de la financiación de los partidos es la percepción de que éstos no adoptan una actitud de austeridad o, en su caso, no la transmiten a la opinión pública.

Por otro lado, hemos de destacar la baja contribución económica de los afiliados. La financiación derivada de cuotas de los afiliados, de las aportaciones de los cargos electos, etc. representa aproximadamente una quinta parte del total de los ingresos. La parte que procede de las subvenciones públicas supone entre dos tercios y cuatro quintos. Esto en el conjunto de los partidos con representación parlamentaria analizados por el Tribunal del Cuentas. La nueva ley establece que las aportaciones de menos de 600 euros anuales sean deducibles de la base del impuesto sobre la renta y que las donaciones nominativas tengan también un trato fiscal favorable. Pero no hay un límite en la proporción de financiación pública, como ocurre en Alemania, donde la financiación pública no puede superar el $50 \%$ de los ingresos anuales del partido. En Francia, las donaciones de particulares están limitadas a 4.600 euros por candidato y a 7.500 por partido, y las donaciones de las empresas están prohibidas. En las elecciones legislativas, la financiación pública se computa por votos 
y escaños a partir de los resultados obtenidos. En Italia, se retiró la financiación pública directa con cargo a los presupuestos y sólo existe la derivada de los resultados electorales. Sin embargo, en aquel país, una ley de febrero de 2006 garantiza que los partidos políticos puedan seguir cobrando el dinero asignado, aún después de la disolución de las cámaras ${ }^{3}$.

Las donaciones privadas han sido el gran caballo de batalla de la nueva ley, que las limita a 100.000 euros para personas físicas o asociaciones, y 150.000 para las que provengan de fundaciones. Eso sí, siempre identificables, nunca anónimas. Es sintomático que excluya de los límites mencionados a las donaciones de inmuebles o a la condonación de deudas, por ejemplo. Si se incluye la condonación de deudas entre las donaciones, el PSOE y el PP declararon, entre 1993 y 2003, unos 24 millones de euros cada uno. Ahora bien, mientras el PP obtuvo el $90 \%$ de dicha cifra como donaciones, el PSOE (separado del PSC) la recibió como condonación de deudas bancarias. Nos podríamos preguntar qué es mejor, si depender de las entidades de crédito o de otros grupos económicos.

La financiación de los partidos presenta deficiencias graves, como las prácticas ilegales o alegales, irregularidades que se acercan en algunos casos a la corrupción, la vorágine de gastos en campaña electoral, la falta de austeridad y de transparencia o la gran dependencia estructural de la financiación públi$\mathrm{ca}^{4}$. Es interesante consultar el informe del Círculo de Economía de diciembre de 1999 (http://www.circuloeconomia.com/opinión99.htm), el cual ya advertía de estas graves deficiencias como causas potenciales de corrupción y de ineficiencia del sistema político, y proponía la necesidad de una reforma del sistema de financiación. Dicho informe sostiene que los problemas más graves de la financiación de los partidos políticos son: 1) crecimiento de los gastos de los partidos y de los candidatos, poniendo énfasis en aquéllos derivados de la publicidad electoral, absolutamente ineficiente para el propósito que se persigue $y$, sin embargo, principal fuente de endeudamiento y déficit crónico de los partidos; 2) escasa autofinanciación de los partidos, producto del bajo índice de afiliación a los mismos; 3) gestión y dirección de los partidos en manos de burocracias internas profesionalizadas, que deciden en última instancia sobre los mecanismos de financiación, e incluso en la confección de las listas; 4) patrimonialización de las instituciones y de las administraciones públicas, ocupando de forma excesiva el espacio público, llegando a situar a personas en cargos de responsabilidad no electiva, repartiéndose por cuotas esos cargos y usando las instituciones como pantalla para su política parti-

3. De esta manera, en Italia se puede cobrar por los partidos de manera doble, por la antigua legislatura ya extinguida y por la nueva, en una especie de cláusula de seguridad económica, más allá de las crisis de gobierno.

4. En este sentido, podemos recordar el acuerdo de transparencia y autolimitación de gastos electorales y financiación de los partidos suscrito en febrero de 2001 por parte de las siete formaciones con presencia en el Parlamento de Cataluña: PSC, CDC, UDC, ERC, PPC, ICV, EUiA. 
dista antes o además de para servir a los ciudadanos. Junto a dicho diagnóstico, el informe mencionado propugna que se elabore un código ético sobre la financiación de los partidos que condene la financiación irregular, que se aumente la financiación proveniente de los particulares por medio de una política de desgravaciones fiscales, la fijación de límites a la cuantía de la financiación pública y de los gastos electorales, siguiendo el modelo alemán de que la cuantía de la financiación pública está condicionada por el volumen de ingresos obtenidos por aportaciones privadas, o el modelo francés de un administrador externo común que canaliza la financiación de las campañas electorales, entre otras medidas.

El informe de la contabilidad de los partidos políticos referido al ejercicio 2004 (en el que nos basamos como ejemplo en el presente estudio) amplió el objeto de control a aquéllos que obtienen representación en los parlamentos autonómicos y han recibido la subvención correspondiente (Acuerdo del Pleno del Tribunal de Cuentas de 23 de febrero de 2005). Dicho informe recoge que el PSOE es el partido con más deuda acumulada, con 62,71 millones de euros, y el PSC, 11,90. Dicha deuda proviene de la integración en la contabilidad ordinaria de las operaciones originadas por la contabilidad electoral. El Tribunal de Cuentas señala que se trata de una deuda vencida pero no pagada, ya que se optó por no contabilizarla mientras no se alcanzara un acuerdo de negociación con las entidades de crédito que otorgaron el préstamo.

Las aportaciones de particulares en 2004 ascienden a 968.703,44 euros de personas físicas, de los que $13.491,58$ proceden de personas identificadas y el resto son donaciones anónimas. Respecto del PSC, su deuda consolidada con entidades de crédito suma 9,14 millones de euros, en los que también se ha incorporado la deuda procedente de las elecciones generales y autonómicas, por valor de 3,79 millones, que se encuentra cancelada a fin de ejercicio. Una de las características de la contabilidad del PSC es la condonación de intereses a cuenta de ingresos, producto de una renegociación del crédito. En el caso de renegociación de deudas y cancelación de intereses, el PSC obtuvo 7,1 millones, y ERC, 2,7. En su conjunto, la deuda de los partidos con las entidades de crédito asciende a 177,6 millones de euros, de los que 8 millones son intereses. De ese total, la deuda vencida asciende a 12,5 millones de euros de principal y 7,7 millones de intereses, distribuida entre EA, IU, PA, PSOE y UDC.

El PP tenía una deuda consolidada con entidades de crédito de 28,4 millones. Otros partidos presentaban el siguiente endeudamiento: CDC, 8,3 millones; UDC, 4,7 millones; CiU, 9 millones; CC, 0,5 millones; IU, 15 millones; ICV, 5,1 millones; PCE, 0,3 millones, PA, 9,2 millones; EA, 2,7 millones; BNG, 2,4 millones; ERC, 2,1 millones; PNV, 14 millones; CHA, 531.292 euros, y PAR, 943.000 euros.

El PP recibió 3,78 millones de euros como donaciones de personas físicas y jurídicas, de los cuales 2,82 procedían de donaciones anónimas. En total, los partidos obtuvieron 7,9 millones de euros en donaciones anónimas. El PSOE obtuvo un total de 968.703,44 euros de personas físicas, de los que sólo $13.491,58$ provenían de personas identificadas. 
Como hemos dicho, el tema de las donaciones anónimas ha sido el gran escollo para suprimirlas en la nueva ley. Recordemos que, con la ley de 2007, las donaciones siempre identificadas tienen el límite de 100.000 euros anuales cuando procedan de la misma persona física o jurídica, que se eleva a 150.000 en el caso de las fundaciones ligadas a partidos políticos.

En el informe de 2004, las aportaciones privadas con donante conocido en ocasiones no cuentan con el órgano social de autorización de las mismas, así, en el caso de CDC, 126.000 euros; del PSOE, 114.091, y del PP, 107.0000.

En el caso de las deudas de los partidos con entidades de crédito ascienden en total a 177,6 millones de euros, de los que 8 millones son intereses. El PSOE acumula una parte importante de dicha deuda, con 75 millones de euros.

El Tribunal de Cuentas denuncia la «insuficiente regulación» de las relaciones entre las fundaciones y los partidos ${ }^{5}$, que hoy recoge la normativa de la nueva ley, ya que limita las donaciones a aquéllas y las integra como objeto de control. Los fondos a fundaciones ascendieron a 2,5 millones de euros (CDC, ERC, EA, ICV, PCE, PSC y UDC) y saldos acreedores en dos formaciones (IU, PCE) por valor de 2,1 millones.

Tanto CiU como el PAR cobraron más de lo que les correspondía en concepto de envíos de propaganda electoral en las elecciones locales de 2003, que, según el TC, deberían de ser reintegrados (CiU, 11.611 euros; PAR, 2.894,47 euros).

También se indica que, según la Ley de restitución o compensación a los partidos políticos de bienes y derechos incautados en la Guerra Civil, recibieron estas compensaciones: PNV, 8,9 millones y un inmueble valorado en unos 3 millones de euros; el PSOE, 1,34 millones; el PCE, 206.751 euros, y ERC, 82.222 euros.

Estando ya a punto de entregar el presente trabajo, el Tribunal de Cuentas aprobó el informe de fiscalización de la contabilidad de los partidos políticos correspondiente al ejercicio de 2005 (24 de abril de 2008). Como aspectos a destacar, podemos hacer notar que las formaciones políticas recibieron del erario público un total de 184,7 millones de euros para su funcionamiento ordinario, y 25,7 derivados de subvenciones por procesos electorales. Recibieron, asimismo, un total de 8,7 millones de euros procedentes de particulares, de los que 7,7 fueron donaciones anónimas. El 40\% de esta última cantidad correspondió al PP, que recibió 3,06 millones; el PSOE, sólo 35.614 euros. Un hecho destacado es que, por primera vez, se ha efectuado un control sobre los grupos políticos y las sedes de ámbito municipal, pero el Tribunal de Cuentas

5. A partir de la entrada en vigor de la nueva ley, estas fundaciones serán controladas por el Tribunal de Cuentas con criterios parecidos a los de los partidos políticos (a lo que se opuso el PP en la aprobación de la Ley). Las ayudas del Ministerio de Cultura para 2007, con un total de 7.018.587,41, se reparten estrictamente por los escaños de la formación a la que están vinculadas. Hay que tener en cuenta que, en muchas ocasiones, esas fundaciones también reciben una subvención de los gobiernos autonómicos con el mismo criterio. 
sostiene que las cifras no reproducen toda la actividad de las organizaciones locales ni de los grupos políticos en las corporaciones locales, que sigue siendo el problema de más difícil detección, debido a la dispersión contable y, en ocasiones, la facilidad para ocultar o falsear las cuentas. La deuda de los partidos con representación en el Congreso de los Diputados con los bancos asciende, en 2005, a 144,8 millones de euros, y una deuda con acreedores en la que se han regularizado 152.782 euros.

En informes anteriores del Tribunal de Cuentas sobre la contabilidad de los partidos, destacan aspectos que podemos comentar, porque son ilustrativos de algunos de los aspectos que surgen reiteradamente. Así, en el de 2002, se informa de 9,6 millones de donaciones privadas y 156,6 millones en financiación pública, la habitual desproporción. En el de 2003, los gastos declarados de funcionamiento ordinario significaron 165 millones de euros en total. Las subvenciones electorales en el 2002 significaron 2,3 millones de euros, correspondientes a las elecciones autonómicas vascas y gallegas de 2001, y, al año siguiente, 51 millones para las elecciones autonómicas y locales. Una de las conclusiones del informe afirma que la práctica totalidad de las formaciones políticas no incorpora la actividad de sus organizaciones locales ni de sus grupos municipales, que quedarían así como en un limbo, aspecto que se reproduce en el 2003. En el ejercicio de 2004, ya se introduce, aunque en municipios de más de 20.000 habitantes (2007). Por otro lado, las operaciones de crédito generan cancelaciones, renegociaciones, que no siempre responden a la claridad contable (caso del PSC). En algunos otros casos, se ha denunciado que los estados contables no son completos (Informe de 1990, muy crítico con $\mathrm{CiU})$. En el caso del PSC, destaca el exceso de gasto en la campaña electoral de las autonómicas, por lo que el Tribunal de Cuentas le impone una multa (2002) y reduce la subvención.

Todo el conjunto de operaciones contables y financieras, de difícil comprensión para un lego en la materia, ponen de manifiesto, sin embargo, la conveniencia del control contable externo en manos del Tribunal de Cuentas, ya que contribuye a la transparencia y a la mejora del uso (buenas prácticas) que realizan los partidos políticos de los fondos públicos. Aunque el juego limpio debe ir acompañado de una cultura de la responsabilidad y de la austeridad.

\section{Aspectos destacables de la nueva ley}

De acuerdo con el artículo 2, los recursos públicos son: a) subvenciones para gastos electorales, de acuerdo con la legislación electoral; $b$ ) subvenciones estatales anuales para gastos de funcionamiento ${ }^{6}$ (reguladas en esta ley) y otras similares que puedan aprobar las comunidades autónomas u otros entes terri-

6. Se toma como referencia una parte en base a los escaños y otra (dos tercios) en base a los votos, pero sin el límite de la barrera mínima del 3\% que establecía la legislación anterior. Esto beneficia a IU, puesto que, en muchas circunscripciones, no supera dicha barrera mínima y sus votos no tenían una contraprestación económica. 
toriales como las corporaciones locales; $c$ ) subvenciones extraordinarias para realizar campañas de propaganda en caso de un referéndum, y d) aportaciones que se aprueben en las cámaras parlamentarias para hacer frente a los gastos de los grupos parlamentarios, en sus diversos niveles territoriales, incluido el ámbito local. El artículo 2 también hace referencia a los diversos tipos de recursos procedentes de la financiación privada (cuotas, aportaciones, rendimientos diversos, donaciones, préstamos o créditos, herencias o legados). Como se puede observar, se da una considerable pretensión de exhaustividad en la referencia a las fuentes.

Las subvenciones serán para hacer frente a los gastos ordinarios de funcionamiento y para los gastos de seguridad (que ya se daban desde 2003) de los partidos con represtación en el Congreso de los Diputados, que se distribuirán en función del número de escaños y de votos obtenidos en las elecciones a dicha cámara. El mismo criterio se seguirá en las subvenciones que provengan de las comunidades autónomas para los partidos con representación en su asamblea legislativa (artículo 3).

En relación con las aportaciones privadas, se establecen unos límites. Destaca que no podrán recibir dinero de empresas que tengan contratos con la Administración (artículo 4.Dos.c), las cuentas bancarias serán abiertas sólo para el fin de la donación, con expresa constancia de todos sus extremos, y cuando sea en especie se necesita la certificación del partido de haberla recibido. No se podrán hacer estas operaciones por medio de personas interpuestas. El artículo 5 establece que las donaciones nunca podrán ser anónimas, que las que procedan de una misma persona física o jurídica no superen los 100.000 euros anuales (con la excepción de la donación de inmuebles). Hasta ahora, eran de un máximo de 6.000 euros, pero, al poder ser anónimas, de poco servía dicho límite.

Se prohíbe que los partidos políticos realicen actividades de carácter mercantil (no se consideran las actividades de promoción o los rendimientos del propio patrimonio). En los ingresos derivados de las actividades propias de los partidos políticos, se exige la identificación del pagador cuando el importe sea igual o superior a 300 euros (artículo 6).

Las cuotas y las aportaciones de los afiliados, adheridos o simpatizantes se realizarán a una cuenta especifica a estos fines (artículo 8).

El régimen tributario de los partidos políticos se caracteriza por la existencia de unas rentas exentas de tributación del impuesto de sociedades: cuotas y aportaciones de los afiliados; subvenciones; donaciones privadas y otros incrementos patrimoniales como consecuencia de adquisiciones a título lucrativo, rendimientos obtenidos en el ejercicio de las actividades propias o procedentes de los bienes y derechos que integran el patrimonio (artículo 10). Las rentas no exentas serán gravadas a un tipo del $25 \%$.

El apartado de las aportaciones de los particulares se guía por el principio de dotarlas de incentivos fiscales: deducción de la base imponible del IRPF, con el límite de 600 euros anuales, y, en el caso específico de las donaciones, se les aplicará una deducción prevista en la Ley del mecenazgo de 2002. 
Los partidos han de llevar los libros de contabilidad, detallados y con la posibilidad de que «en todo momento" se pueda conocer su situación financiera y patrimonial (artículo 14). El artículo 14, apartado cuatro, afirma: «Las cuentas anuales consolidadas se extenderán a los ámbitos estatal, autonómico, comarcal y provincial. Las cuentas anuales consolidadas de federaciones de partidos y coaliciones incluirán las de los partidos federados y coaligados». Todas las cuentas reflejadas en la correspondiente memoria deberán presentarse ante el Tribunal de Cuentas antes del 30 de junio de cada año. Los partidos se han de responsabilizar de llevar un control interno de su contabilidad, que se incorporará a la memoria anual que se lleva al Tribunal de Cuentas. El control externo está en manos del Tribunal de Cuentas: comprende la fiscalización de la legalidad de los recursos, pero también de la regularidad contable de los mismos (artículo 16.dos). El informe del Tribunal de Cuentas se emitirá en el plazo de seis meses (artículo 16, tres) (sic), afirmación que contrasta con la lentitud con la que se han desarrollado los informes hasta ahora, por lo menos los relativos a los estados contables de los partidos con representación parlamentaria (otra cosa son los informes sobre la contabilidad electoral, más breves e inmediatos).

El título VI de la Ley se dedica a regular el régimen sancionador, pudiendo imponer multas y reducir o eliminar las subvenciones para gastos de funcionamiento, en los supuestos de no cumplir con lo dispuesto en la ley (artículo 17 y s.).

La disposición transitoria tercera fija la cantidad a recibir por los partidos políticos para el ejercicio 2008 en 78.100,00 millones de euros y 4.010,00 millones para seguridad, que se adaptarán cada año "como mínimo» al incremento del IPC (disposición adicional sexta). Ello supone, como ya hemos indicado más arriba, un aumento del 20\% respecto del año 2007.

La disposición adicional sexta contiene la novedosa introducción de las fundaciones y asociaciones vinculadas a los partidos políticos como sujetos que entran dentro del radio de acción de la Ley. Asimismo, el régimen de las donaciones que se pueden realizar a las mismas se fija de la siguiente forma: A) El límite de las donaciones de personas físicas o jurídicas será de 150.000 euros. B) No les será de aplicación la prohibición del art. 4.dos, c), o sea, que se abre la puer$t a$ a que las fundaciones y asociaciones vinculadas orgánicamente a los partidos políticos puedan «aceptar o recibir, directa o indirectamente, donaciones de empresas privadas que, mediante contrato vigente, presenten sus servicios o realicen obras para las administraciones públicas, organismos públicos o empresas de capital mayoritariamente público. C) Las donaciones de personas jurídicas por importe superior a 120.000 euros precisarán que la donación se formalice en escritura pública. En todo caso, el diseño de la ley, si bien permite ampliar el control del Tribunal de Cuentas, también aumenta la capacidad de las fundaciones y de las asociaciones vinculadas a los partidos políticos de ser una fuente importante de financiación de los mismos de forma indirecta ${ }^{7}$.

7. Éste fue un caballo de batalla de CiU en la negociación de la ley. 


\section{Consideraciones finales}

Una valoración global de la nueva ley ha de tener en cuenta el hecho de que los partidos presentes en las Cortes Generales no aprobarán nunca una regulación deficiente para ellos mismos. La nueva ley de financiación de los partidos políticos se aprueba finalmente con el voto en contra del PP, más estratégico que otra cosa, ya que, si bien no participa del consenso final de los otros grupos, también se beneficia del resultado de la nueva regulación.

La nueva ley prohíbe las donaciones anónimas, a cambio de un aumento suculento de la cantidad de dinero público de subvención directa que recibirán los partidos. En efecto, como hemos visto, la nueva ley aumenta en un $20 \%$ la subvención para el funcionamiento ordinario (sin contar las cantidades relacionadas con los gastos electorales o con la seguridad). Por otro lado, hemos de destacar la baja contribución económica de los afiliados. En efecto, la financiación derivada de las cuotas de los afiliados, de las aportaciones de los cargos electos, etc. representa aproximadamente sólo una quinta parte del total de los ingresos.

La nueva ley establece que las aportaciones de particulares de menos de 600 euros anuales sean deducibles de la base del impuesto sobre la renta y que las donaciones nominativas tengan también un trato fiscal favorable. Pero no hay un límite en la proporción de financiación pública, como ocurre en Alemania, donde la financiación pública no puede superar el 50\% de los ingresos anuales del partido. De momento, con el aumento mencionado del 20\% de un año a otro, se nos muestra un trato discriminatorio en relación con otros colectivos, se encubre la mala gestión o el derroche y se ignora la ejemplaridad en el uso riguroso de los recursos públicos.

Las donaciones privadas han sido el gran caballo de batalla de la nueva ley, que las limita a 100.000 euros y a 150.000 para las que vayan a parar a las fundaciones dependientes de los partidos. Eso sí, siempre identificables, nunca anónimas. Ahora bien, es sintomático que se excluya de los límites mencionados a las donaciones de inmuebles, o la condonación de deudas, por ejemplo, que fácilmente comportarán cantidades más altas. Además, si bien la disposición adicional sexta incluye a las fundaciones y asociaciones vinculadas a los partidos políticos como sujetos que entran dentro del ámbito de regulación de la ley, el régimen de las donaciones que se pueden realizar a las mismas abre la puerta a que las fundaciones y asociaciones vinculadas orgánicamente a los partidos políticos puedan «aceptar o recibir, directa o indirectamente, donaciones de empresas privadas que, mediante contrato vigente, presenten sus servicios o realicen obras para las administraciones públicas, organismos públicos o empresas de capital mayoritariamente público. Las donaciones de personas jurídicas por importe superior a 120.000 euros precisarán que la donación se formalice en escritura pública» (sic). La nueva ley, a cambio de ampliar el control del Tribunal de Cuentas, aumenta la capacidad de las fundaciones y asociaciones vinculadas, de ser una fuente importante de financiación de los partidos de forma indirecta. 
Por su parte, el criterio de financiación derivado de los resultados electorales, al suprimir el elemento de la barrera mínima del 3\% de los votos por circunscripción previsto en la ley anterior, beneficia a los partidos pequeños con representación parlamentaria, en un guiño a los mismos.

Se constata una progresiva ampliación del objeto de control (ámbito local, fundaciones y asociaciones vinculadas, etc.), pero, seguramente, todavía quedan zonas de penumbra, como el control contable de los comités locales de los partidos a lo largo del territorio, en los pequeños municipios, etc. En el informe de 2004, comentado aquí, sin ir más lejos, todos los partidos muestran deficiencias en la comunicación e información de los ámbitos local y comarcal, que deberán corregir de cara al futuro.

Como consideración final, cabe destacar que la actividad de control externo de la contabilidad de los partidos políticos, la fiscalización contable y el enjuiciamiento de las cuentas de los partidos, de manera integrada y sistemática, tal y como se refleja en los informes del Tribunal de Cuentas, permite un conocimiento del uso realizado del dinero público y, en su caso, detectar irregularidades o deficiencias que hemos de considerar de especial trascendencia. En efecto, a pesar del carácter técnico-contable de esos informes, su divulgación y conocimiento es una manifestación de transparencia administrativa y un imperativo ético, dos aspectos que, a mi juicio, son ineludibles en cualquier reflexión sobre la democracia de partidos.

\section{Referencias bibliográficas}

Álvarez Conde, E. y otros (1994). La financiación de los partidos. Madrid: Centro de Estudios Constitucionales.

ARGANDOÑA, A. (2001). «La financiación de los partidos políticos y la corrupción en las empresas». Papeles de Ética, Economía y Dirección, número 6.

Balaguer Callejón, F. (1999). «La financiación de los partidos políticos en España». Nomos. Le attualittà nel diritto, 1.

Bautista PlazA, D. (2006). La función constitucional de los partidos políticos. Granada: Comares.

BLANCO VALDÉS, Roberto L. (2001). Las conexiones políticas: partidos, estado, sociedad. Madrid: Alianza Editorial.

CAstillo Vera, P. del (1985). La financiación de partidos y candidatos en las democracias occidentales. Madrid: Siglo XXI.

- (1992). La financiación de los partidos políticos: propuestas para una reforma. Madrid: Fundación para el Análisis y los Estudios Sociales.

CORTÉS BURETA, P. (2003). Recursos públicos y partidos políticos: balance y perspectivas de reforma. Madrid: Centro de Estudios Políticos y Constitucionales,

- (2008). Com es financen els partits polítics. Vic: Eumo Editorial.

Criado de Diego, M. (2007). Representación, Estado y democracia. Valencia: Tirant Lo Blanch.

FERNÁNDEZ EsPINOSA, G. (2006). El control externo de la contabilidad electoral. Valencia: Sindicatura de Comptes de la Comunitat Valenciana.

GALIACHO, J. L. (1995). Filesa: las tramas del dinero negro en la política. Madrid: Temas de Hoy. 
GONZALEZ-VARAS IbÁÑEZ, S. (1995). La financiación de los partidos políticos. Madrid: Dykinson.

Holgado GonZÁlez, M. (2003). La financiación de los partidos politicos en España. Valencia: Tirant Lo Blanch.

Martínez Cuevas, M. D. (2006). Régimen jurídico de los partidos políticos. Madrid: Marcial Pons.

Parlamento Europeo. Dirección General de Estudios (1991). La financiación de los partidos políticos en los estados miembros de la Comunidad Europea. 2a ed. rev. Luxemburgo: Oficina de Publicaciones de las Comunidades europeas.

ROMERO Flores, B. (2005). Partidos politicos y responsabilidad penal: la financiación irregular. Barcelona: Atelier.

SÁnChez Soler, M. (1990). Partidos políticos: las tramas del dinero negro. Del sumario Sanchis-Naseiro a la reforma de la ley electoral. Madrid: Tiempo.

TRIBUNAL DE CUENTAS (2001). Moción relativa a la modificación de la normativa sobre financiación y fiscalización de los partidos políticos. Madrid: Tribunal de Cuentas.

\section{Enlaces web}

Financiación de los partidos y las elecciones (Universidad Carlos III de Madrid): http://turan.uc3m.es/uc3m/dpto/PU/dppu02/finan.htm.

Recursos de interés sobre financiación de los partidos (derecho comparado): http://turan.uc3m.es/uc3m/dpto/PU/dppu02/lin.htm. 


\section{Anexos}

Anexo 1. Resumen, en euros, de los gastos declarados justificados y de las propuestas formuladas por el Tribunal de Cuentas en el informe de fiscalización de la contabilidad electoral de las elecciones a Cortes Generales de 14 de marzo de 2004, Resolución de 28 de junio de 2005, aprobada por la Comisión Mixta para las Relaciones con el Tribunal de Cuentas (BOE, $18 / 8 / 2005)$

\begin{tabular}{|c|c|c|c|}
\hline $\begin{array}{r}\text { por } \\
\text { Incren } \\
\text { env }\end{array}$ & $\begin{array}{l}\text { Gastos justificados } \\
\text { or operaciones ordinarias } \\
\text { ementados en los gastos por } \\
\text { nvíos no subvencionables }\end{array}$ & $\begin{array}{c}\text { Gastos justificados } \\
\text { subvencionables } \\
\text { por envíos electorales }\end{array}$ & $\begin{array}{c}\text { Propuesta de } \\
\text { reducción de la } \\
\text { subvención electoral }\end{array}$ \\
\hline Partido Socialista Obrero Español & $10.640 .599,90$ & $5.253 .191,87$ & - \\
\hline Partido Popular & $12.456 .996,65$ & $6.138 .290,70$ & - \\
\hline Partit dels Socialistes de Catalunya & $1.800 .914,05$ & $937.078,20$ & - \\
\hline Convergència i Unió & $2.144 .080,51$ & $937.041,30$ & - \\
\hline Izquierda Unida & $1.380 .123,87$ & $937.041,30$ & - \\
\hline Esquerra Republicana de Catalunya & $799.804,75$ & $1.546 .905,78$ & - \\
\hline Eusko Alderdi Jeltzalea-Partido Nacionalista Vasco & $650.948,29$ & $318.075,48$ & - \\
\hline Coalición Canaria & $401.393,61$ & $251.999,27$ & - \\
\hline Iniciativa per Catalunya Verds-Esquerra Unida i Alternativa & $417.506,93$ & - & - \\
\hline Bloque Nacionalista Galego & $841.041,56$ & - & - \\
\hline Unión del Pueblo Navarro en coalición con el Partido Popular & $184.624,81$ & $81.326,99$ & $2.220,00$ \\
\hline Esquerra Unida del País Valencià-Izquierda Republicana: Entesa & $93.130,22$ & - & - \\
\hline Chunta Aragonesista & 271.428 .07 & - & - \\
\hline Eusko Alkartasuna & $665.700,98$ & - & - \\
\hline Nafarroa Bai & $169.729,89$ & - & - \\
\hline Entesa Catalana de Progrés & $1.919 .269,87$ & $937.106,46$ & - \\
\hline
\end{tabular}


Anexo 2. Cuadro de las subvenciones públicas recibidas por los partidos políticos en el ejercicio de 2004

Subvenciones de funcionamiento ordinario (en euros)

\begin{tabular}{|c|c|c|c|c|c|c|}
\hline Formaciones políticas & $\begin{array}{c}\text { Subvención } \\
\text { estatal }\end{array}$ & $\begin{array}{l}\text { Gobiernos } \\
\text { autonómicos }\end{array}$ & Cortes Generales & $\begin{array}{l}\text { Asambleas legislativas } \\
\text { autonómicas y ciudades } \\
\text { autónomas }\end{array}$ & $\begin{array}{l}\text { Entidades } \\
\text { locales }\end{array}$ & Total \\
\hline \multicolumn{7}{|c|}{ Formaciones con representación en las Cortes Generales } \\
\hline Bloque Nacionalista Galego & $512.788,86$ & & $137.095,21$ & $466.315,08$ & $407.562,14$ & $1.523 .761,29$ \\
\hline Chunta Aragonesista & $208.271,36$ & & $62.848,52$ & $347.829,14$ & $155.588,27$ & $774.537,29$ \\
\hline Coalición Canaria & $582.290,09$ & & $572.861,70$ & $436.022,64$ & $792.706,62$ & $2.384 .581,05$ \\
\hline $\begin{array}{l}\text { Convergència Democràtica } \\
\text { de Catalunya } \\
\text { Federación Convergència }\end{array}$ & $1.541 .886,36$ & & $146.187,12$ & $1.690 .075,98$ & & \\
\hline i Unió & $38.429,33$ & & $722.516,57$ & $4.386 .401,98$ & $1.842 .496,18$ & $6.989 .844,06$ \\
\hline Eusko Alkartasuna & $200.408,63$ & & $62.848,52$ & $589.080,00$ & $926.613,84$ & 1.778 .950 \\
\hline \multicolumn{6}{|l|}{ Esquerra Republicana } & $5.213 .802,07$ \\
\hline Iniciativa per Catalunya Verds & $437.943,65$ & & $11.398,05$ & $1.177 .975,86$ & $1.275 .098,71$ & $2.902 .416,27$ \\
\hline Izquierda Unida & $1.921 .664,72$ & $200.333,00$ & $385.578,00$ & $2.770 .067,47$ & $3.568 .541,38$ & $8.846 .184,57$ \\
\hline Nafarroa Bai & $1.921 .664,72$ & & $51.450,47$ & $176.961,64$ & & \\
\hline Partido Andalucista & $86.505,26$ & & $11.398,05$ & $528.758,85$ & $1.005,752,14$ & $1.632 .414,30$ \\
\hline Partido Nacionalista Vasco & $1.079 .717,19$ & $1.710 .714,00$ & $651.297,15$ & $1.051 .794,50$ & $2.027 .220,14$ & $6.520 .742,98$ \\
\hline Partido Popular & $25.126 .248,84$ & $945.723,00$ & $5.118 .579,00$ & $16.627 .693,33$ & $13.640 .977,91$ & $61.459 .228,08$ \\
\hline $\begin{array}{l}\text { Partit dels Socialistes } \\
\text { de Catalunya }\end{array}$ & $3.654 .193,15$ & & & $4.176 .724,06$ & $3.320 .092,77$ & $11.151 .009,98$ \\
\hline \multicolumn{7}{|l|}{ Partido Socialista Obrero } \\
\hline Español & $22.615 .831,22$ & $702.319,00$ & $4.316 .555,56$ & $14.812 .535,39$ & $12.745 .045,90$ & 55.192 .299 \\
\hline \multicolumn{7}{|l|}{ Unió Democràtica } \\
\hline de Catalunya & $502.925,05$ & & & & $39.186,74$ & $542.111,79$ \\
\hline Unión del Pueblo Navarro & $349.184,68$ & & & $826.687,05$ & $54.746,48$ & $1.230 .636,21$ \\
\hline Entesa Catalana de Progrés & & & $372.520,84$ & & & $372.520,84$ \\
\hline Grupo Mixto & & & $244.521,64$ & & & $244,521,64$ \\
\hline
\end{tabular}


Anexo 2. Cuadro de las subvenciones públicas recibidas por los partidos políticos en el ejercicio de 2004 (continución).

Subvenciones de funcionamiento ordinario (en euros)

\begin{tabular}{|c|c|c|c|c|c|c|}
\hline Formaciones políticas & $\begin{array}{l}\text { Subvención } \\
\text { estatal }\end{array}$ & $\begin{array}{l}\text { Gobiernos } \\
\text { autonómicos }\end{array}$ & Cortes Generales & $\begin{array}{l}\text { Asambleas legislativas } \\
\text { autonómicas y ciudades } \\
\text { autónomas }\end{array}$ & $\begin{array}{l}\text { Entidades } \\
\text { locales }\end{array}$ & Total \\
\hline \multicolumn{7}{|c|}{ Formaciones con representación en las Cortes Generales } \\
\hline Bloque Nacionalista Galego & $512.788,86$ & & $137.095,21$ & $466.315,08$ & $407.562,14$ & $1.523 .761,29$ \\
\hline Chunta Aragonesista & $208.271,36$ & & $62.848,52$ & $347.829,14$ & $155.588,27$ & $774.537,29$ \\
\hline Coalición Canaria & $582.290,09$ & & $572.861,70$ & $436.022,64$ & $792.706,62$ & $2.384 .581,05$ \\
\hline \multicolumn{7}{|c|}{ Otras formaciones con representación en las asambleas legislativas autonómicas } \\
\hline \multirow{2}{*}{\multicolumn{4}{|c|}{ Aralar }} & $211.536,00$ & $104.401,85$ & $315.937,85$ \\
\hline \multirow{2}{*}{\multicolumn{4}{|c|}{$\begin{array}{l}\text { Convergencia de Demócratas } \\
\text { de Navarra }\end{array}$}} & & & \\
\hline & & & & $\begin{array}{l}211.536,00 \\
322600,65\end{array}$ & $\begin{array}{r}9.330,02 \\
162364.64\end{array}$ & $\begin{array}{l}220.866,02 \\
484965,29\end{array}$ \\
\hline \multirow{2}{*}{\multicolumn{4}{|c|}{$\begin{array}{l}\text { Partido Independiente } \\
\text { de Lanzarote }\end{array}$}} & & & \\
\hline & & & & $103.092,00$ & $48.280,08$ & $151.371,08$ \\
\hline & $51.276,00$ & $20.983,16$ & $72.269,16$ \\
\hline \multirow{2}{*}{\multicolumn{4}{|c|}{$\begin{array}{l}\text { Partido Regionalista } \\
\text { de Cantabria }\end{array}$}} & & & \\
\hline & & & & $368.026,20$ & $48.275,91$ & $416.302,11$ \\
\hline \multicolumn{4}{|l|}{$\begin{array}{l}\text { Partit Socialista de Menorca- } \\
\text { Entesa Nacionalista }\end{array}$} & $42.547,00$ & $31.444,76$ & $73.991,76$ \\
\hline \multirow{2}{*}{\multicolumn{4}{|c|}{$\begin{array}{l}\text { Partit Socialista de Mallorca- } \\
\text { Entesa Nacionalista }\end{array}$}} & & & \\
\hline & & & & $84.953,00$ & $66,334,32$ & $151.287,32$ \\
\hline \multicolumn{4}{|l|}{ Unió Mallorquina } & $39.600,00$ & $53.272,12$ & $92.872,12$ \\
\hline \multirow{2}{*}{\multicolumn{4}{|c|}{$\begin{array}{l}\text { Unión del Pueblo Leonés } \\
\text { Grupo Mixto }\end{array}$}} & $142.725,32$ & $36.378,92$ & $179.104,24$ \\
\hline & & & & $150.015,50$ & $20.946,02$ & $171.685,39$ \\
\hline \multicolumn{5}{|c|}{ Otras formaciones con representación en las ciudades autónomas } & $138.015,50$ & $138.015,50$ \\
\hline \multicolumn{5}{|c|}{ Otras formaciones con representación en corporaciones locales } & $2.529 .072,42$ & $2.529 .072,42$ \\
\hline Total & $60.264 .290,00$ & $3.559 .089,00$ & $13.052 .884,03$ & $52.467 .838,78$ & $46.280 .233,55$ & $175.624 .335,36$ \\
\hline
\end{tabular}

En el importe de la subvención estatal $(60.264 .290,00 €)$, se incluye la correspondiente al funcionamiento ordinario $(57.264 .430 €)$ y las asignaciones para gastos de seguridad (2.999.860 €).

Fuente: Informe de fiscalización de los estados contables del ejercicio 2004 de los partidos políticos con representación parlamentaria en las Cortes Generales o en las Asambleas Legislativas de las Comunidades Autónomas, p. 20. 
Anexo 3. Cuadro de las subvenciones recibidas por los partidos políticos con motivo de los procesos electorales celebrados. Al margen de las cantidades anteriores, hay que añadir las cantidades abonadas con motivo de las diversas elecciones celebradas.

Subvenciones electorales (en euros)

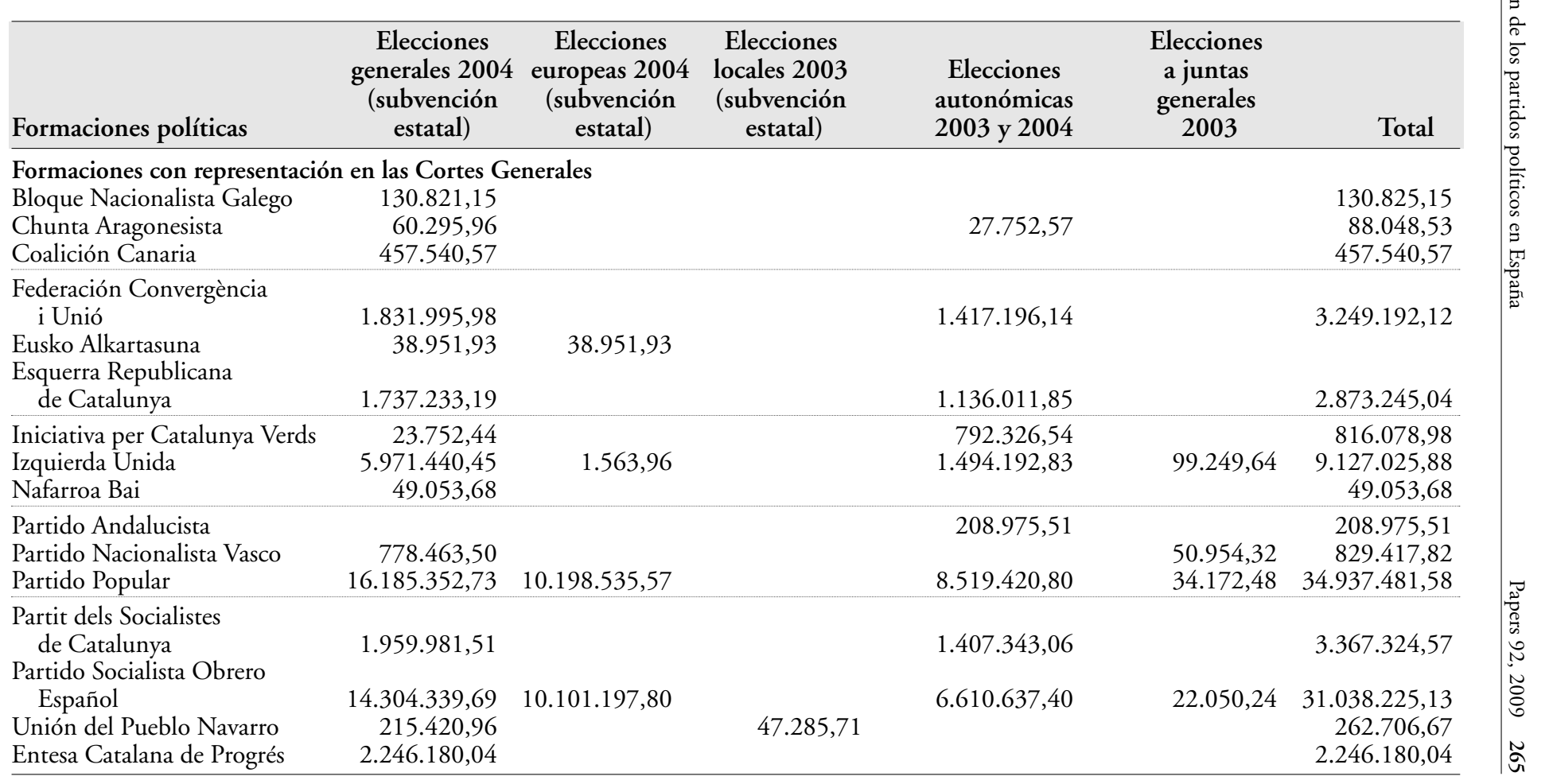


Anexo 3. Cuadro de las subvenciones recibidas por los partidos políticos con motivo de los procesos electorales celebrados. $\mathrm{Al}$ margen de las cantidades anteriores, hay que añadir las cantidades abonadas con motivo de las diversas elecciones celebradas (continuación).

\section{Subvenciones electorales (en euros)}

\begin{tabular}{|c|c|c|c|c|c|c|}
\hline Formaciones políticas & $\begin{array}{c}\text { Elecciones } \\
\text { generales } 2004 \\
\text { (subvención } \\
\text { estatal) }\end{array}$ & $\begin{array}{c}\text { Elecciones } \\
\text { europeas } 2004 \\
\text { (subvención } \\
\text { estatal) }\end{array}$ & $\begin{array}{c}\text { Elecciones } \\
\text { locales } 2003 \\
\text { (subvención } \\
\text { estatal) }\end{array}$ & $\begin{array}{c}\text { Elecciones } \\
\text { autonómicas } \\
2003 \text { y } 2004\end{array}$ & $\begin{array}{l}\text { Elecciones } \\
\text { a juntas } \\
\text { generales } \\
2003\end{array}$ & Total \\
\hline \multicolumn{7}{|c|}{ Resto de formaciones políticas } \\
\hline Aralar & & & $48.701,45$ & & $10.879,73$ & $59.581,18$ \\
\hline Partido Riojano & & & $30.949,21$ & $42.387,89$ & & $73.337,10$ \\
\hline \multicolumn{7}{|l|}{ Partido Regionalista } \\
\hline de Cantabria & & & $93.402,97$ & $96.351,31$ & & $189.754,28$ \\
\hline PSM-Entesa Nacionalista & & & $86.797,03$ & $107.926,45$ & & $194.723,48$ \\
\hline Unió Mallorquina & & & $32.643,77$ & $87.458,11$ & & $120.101,88$ \\
\hline Unión del Pueblo Leonés & & & $76.100,92$ & $14.300,70$ & & $90.401,62$ \\
\hline Galeusca & & $1.878 .965,31$ & & & & $1.878 .965,31$ \\
\hline \multicolumn{7}{|l|}{ Coalición Europa } \\
\hline de los Pueblos & & $1.060 .800,67$ & & & & $1.060 .800,67$ \\
\hline Coalición Europea & & $250.871,47$ & & & & $250.871,47$ \\
\hline Coalición PNV-EA & & & & & $42.562,36$ & $42.562,36$ \\
\hline Otras formaciones & & & $272.088,73$ & $63.111,06$ & $10.402,28$ & $345.602,07$ \\
\hline Total & $45.990 .827,78$ & $25.052 .513,78$ & $687.969,79$ & $22.025 .399,22$ & $270.271,05$ & $94.026 .974,62$ \\
\hline
\end{tabular}

Fuente: Informe de fiscalización de los estados contables del ejercicio 2004 de los partidos políticos con representación parlamentaria en las Cortes Generales o en las Asambleas Legislativas de las Comunidades Autónomas, p. 21. 
Anexo 4. Cuadro de las subvenciones públicas recibidas por los partidos políticos en el ejercicio de 2005

Subvenciones anuales de funcionamiento ordinario (en euros)

\begin{tabular}{|c|c|c|c|c|c|c|}
\hline Formaciones políticas & $\begin{array}{l}\text { Subvención } \\
\text { estatal }\end{array}$ & $\begin{array}{c}\text { Gobiernos } \\
\text { autonómicos }\end{array}$ & $\begin{array}{c}\text { Cortes } \\
\text { Generales }\end{array}$ & $\begin{array}{c}\text { Asambleas legislativas } \\
\text { autonómicas y ciudades } \\
\text { autónomas }\end{array}$ & $\begin{array}{l}\text { Entidades } \\
\text { locales }\end{array}$ & Total \\
\hline $\begin{array}{l}\text { Formaciones con representaciór } \\
\text { Bloque Nacionalista Galego } \\
\text { Coalición Canaria } \\
\text { Convergència Democràtica } \\
\text { de Catalunya }\end{array}$ & $\begin{array}{r}\text { n en las Cortes G } \\
465.222,41 \\
568.027,85 \\
\\
1.459 .749,62\end{array}$ & nerales & $\begin{array}{l}142.530,96 \\
567.765,20\end{array}$ & $\begin{array}{l}457.138,08 \\
464.018,64\end{array}$ & $\begin{array}{l}343.503,48 \\
831.870,51 \\
165.060,01\end{array}$ & $\begin{array}{l}1.408 .394,93 \\
2.431 .682,20 \\
1.624 .809,63\end{array}$ \\
\hline $\begin{array}{l}\text { Chunta Aragonesista } \\
\text { Federación Convergència i Unió } \\
\text { Eusko Alkartasuna }\end{array}$ & $\begin{array}{r}215.775,54 \\
49.262,25 \\
193.509,84\end{array}$ & $525.620,80$ & $\begin{array}{r}71.265,60 \\
705.558,51 \\
71.265,60\end{array}$ & $\begin{array}{r}384.883,66 \\
4.848 .716,97 \\
600.901,47\end{array}$ & $\begin{array}{r}161.910,28 \\
1.873 .025,31 \\
966.467,99\end{array}$ & $\begin{array}{r}833.835,08 \\
7.476 .563,04 \\
2.357 .765,70\end{array}$ \\
\hline $\begin{array}{l}\text { Esquerra Republicana } \\
\text { de Catalunya } \\
\text { Iniciativa per Catalunya-Verds } \\
\text { Izquierda Unida }\end{array}$ & $\begin{array}{r}1.534 .169,02 \\
497.238,86 \\
1.797 .738,61\end{array}$ & $260.853,72$ & $\begin{array}{l}442.044,17 \\
385.194,61\end{array}$ & $\begin{array}{r}2.642 .211,62 \\
1.278 .707,08 \\
3.020 .45,05\end{array}$ & $\begin{array}{l}1.269 .237,60 \\
1.358 .974,23 \\
3.492 .298,81\end{array}$ & $\begin{array}{l}5.887 .569,41 \\
3.134 .920,17 \\
8.956 .492,80\end{array}$ \\
\hline $\begin{array}{l}\text { Nafarroa Bai } \\
\text { Partido Nacionalista Vasco } \\
\text { Partido Popular }\end{array}$ & $\begin{array}{r}160.379,00 \\
1.112 .084,85 \\
24.621 .324,85\end{array}$ & $\begin{array}{l}1.576 .862,39 \\
1.045 .777,17\end{array}$ & $\begin{array}{r}71.265,60 \\
670.949,81 \\
5.099 .290,48\end{array}$ & $\begin{array}{r}845.007,04 \\
17.415 .094,92\end{array}$ & $\begin{array}{r}2.119 .105,32 \\
14.223 .826,94\end{array}$ & $\begin{array}{r}231.644,60 \\
6.324 .009,41 \\
62.405 .314,36\end{array}$ \\
\hline $\begin{array}{l}\text { Partit dels Socialistes } \\
\text { de Catalunya } \\
\text { Partido Socialista Obrero Español } \\
\text { Unió Democràtica de Catalunya }\end{array}$ & $\begin{array}{r}3.876 .437,15 \\
24.118 .599,42 \\
\text { a } \quad 470.162,42\end{array}$ & $1.133 .126,61$ & $4.804 .342,67$ & $\begin{array}{r}4.627 .265,41 \\
16.084 .542,87\end{array}$ & $\begin{array}{r}3.356 .394,39 \\
13.167 .373,26 \\
57.254,87\end{array}$ & $\begin{array}{r}11.860 .096,95 \\
59.307 .984,83 \\
527.417,29\end{array}$ \\
\hline $\begin{array}{l}\text { Unión del Pueblo Navarro } \\
\text { Entesa Catalana de Progrés } \\
\text { Grupo Mixto }\end{array}$ & $330.038,31$ & & $\begin{array}{l}403.478,88 \\
194.097,24\end{array}$ & $868.322,00$ & $63.823,44$ & $\begin{array}{r}1.262 .193,75 \\
403.478,88 \\
194.097,24\end{array}$ \\
\hline
\end{tabular}


Anexo 4. Cuadro de las subvenciones públicas recibidas por los partidos políticos en el ejercicio de 2005 (continuación).

Subvenciones anuales de funcionamiento ordinario (en euros)

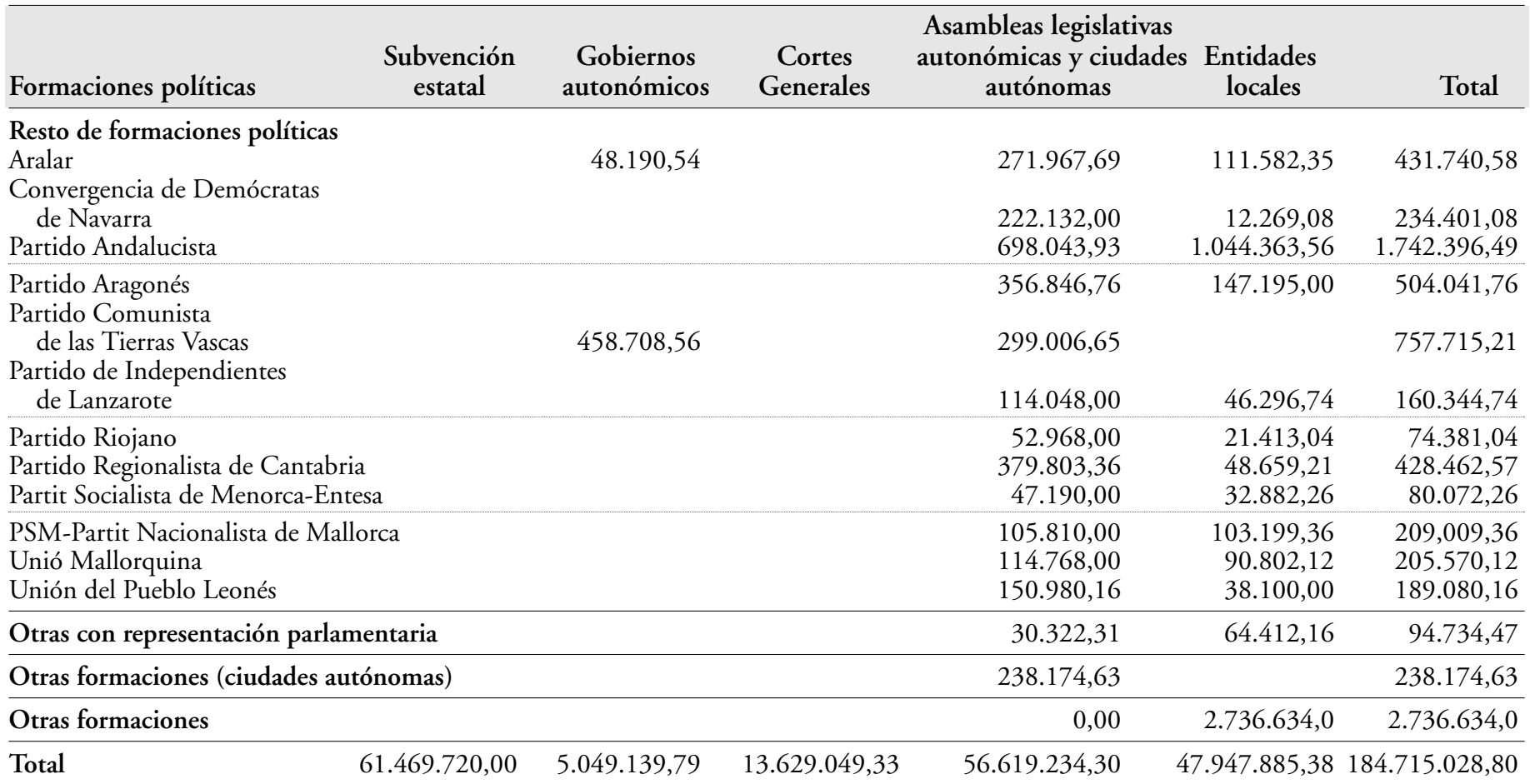

En el apartado de subvención estatal, se incluye tanto la subvención estatal de funcionamiento ordinario (58.409.720 €) como las asignaciones para seguridad. Fuente: Informe de fiscalización de los estados contables del ejercicio 2005 de los partidos políticos con representación en las Cortes Generales o en las Asambleas Legislativas de las Comunidades Autónomas, p. 20. 
Anexo 5. Subvenciones electorales recibidas por los partidos políticos. Ejercicio 2005 (en euros)

\begin{tabular}{|c|c|c|c|c|c|}
\hline Formaciones políticas & $\begin{array}{c}\text { Elecciones } \\
\text { generales 2004 } \\
\text { (subvención estatal) }\end{array}$ & $\begin{array}{c}\text { Elecciones } \\
\text { europeas 2004 } \\
\text { (subvención estatal) } \\
\end{array}$ & $\begin{array}{c}\text { Elecciones locales } \\
2003 \\
\text { (subvención estatal) } \\
\end{array}$ & $\begin{array}{l}\text { Elecciones autonómicas } \\
\text { de } 2003 \text { a } 2005\end{array}$ & Total \\
\hline $\begin{array}{l}\text { Formaciones con representació } \\
\text { Bloque Nacionalista Galego } \\
\text { Coalición Canaria } \\
\text { Chunta Aragonesista }\end{array}$ & $\begin{array}{c}\text { lón en las Cortes Gener } \\
14.536,13 \\
107.324,33 \\
14.143,49\end{array}$ & & $\begin{array}{r}69.668,84 \\
116.006,16 \\
19.600,58 \\
\end{array}$ & $\begin{array}{r}810.862,75 \\
27.752,57\end{array}$ & $\begin{array}{r}895.067,72 \\
223.330,49 \\
61.496,64\end{array}$ \\
\hline $\begin{array}{l}\text { Federación Convergència } \\
\text { i Unió } \\
\text { Eusko Alkartasuna } \\
\text { Esquerra Republicana } \\
\quad \text { de Catalunya }\end{array}$ & $\begin{array}{r}203.360,65 \\
9.136,91 \\
\\
398.027,37\end{array}$ & & $168.970,97$ & & $\begin{array}{r}372.331,62 \\
9.136,91 \\
\\
635.357,64\end{array}$ \\
\hline $\begin{array}{l}\text { Iniciativa per Catalunya Verds } \\
\text { Izquierda Unida } \\
\text { Nafarroa Bai }\end{array}$ & $\begin{array}{r}43.839,58 \\
403.485,50 \\
11.506,42 \\
\end{array}$ & $173.004,12$ & $\begin{array}{l}172.222,04 \\
339.186,75\end{array}$ & $1.365 .180,51$ & $\begin{array}{r}216.061,62 \\
2.280 .856,88 \\
11.506,42 \\
\end{array}$ \\
\hline $\begin{array}{l}\text { Entesa Catalana de Progrés } \\
\text { Partido Nacionalista Vasco } \\
\text { Partido Popular }\end{array}$ & $\begin{array}{r}610.196,29 \\
190.560,27 \\
2.409 .934,62\end{array}$ & $1.291 .766,50$ & $\begin{array}{r}14.887,94 \\
1.873 .925,17\end{array}$ & $3.382 .749,21$ & $\begin{array}{r}610.196,29 \\
205.448,21 \\
8.958 .375,50\end{array}$ \\
\hline $\begin{array}{l}\text { Partit dels Socialistes } \\
\text { de Catalunya } \\
\text { Partido Socialista Obrero } \\
\text { Español }\end{array}$ & $\begin{array}{r}459.172,86 \\
1.589 .452,08\end{array}$ & $1.122 .355,31$ & $\begin{array}{r}348.549,53 \\
1.262 .666,53\end{array}$ & $2.921 .605,25$ & $\begin{array}{r}807.722,39 \\
6.896 .079,17\end{array}$ \\
\hline Unión del Pueblo Navarro & $48.310,84$ & & $17.515,02$ & & $65.825,86$ \\
\hline
\end{tabular}


Anexo 5. Subvenciones electorales recibidas por los partidos políticos. Ejercicio 2005 (en euros) (continuación).

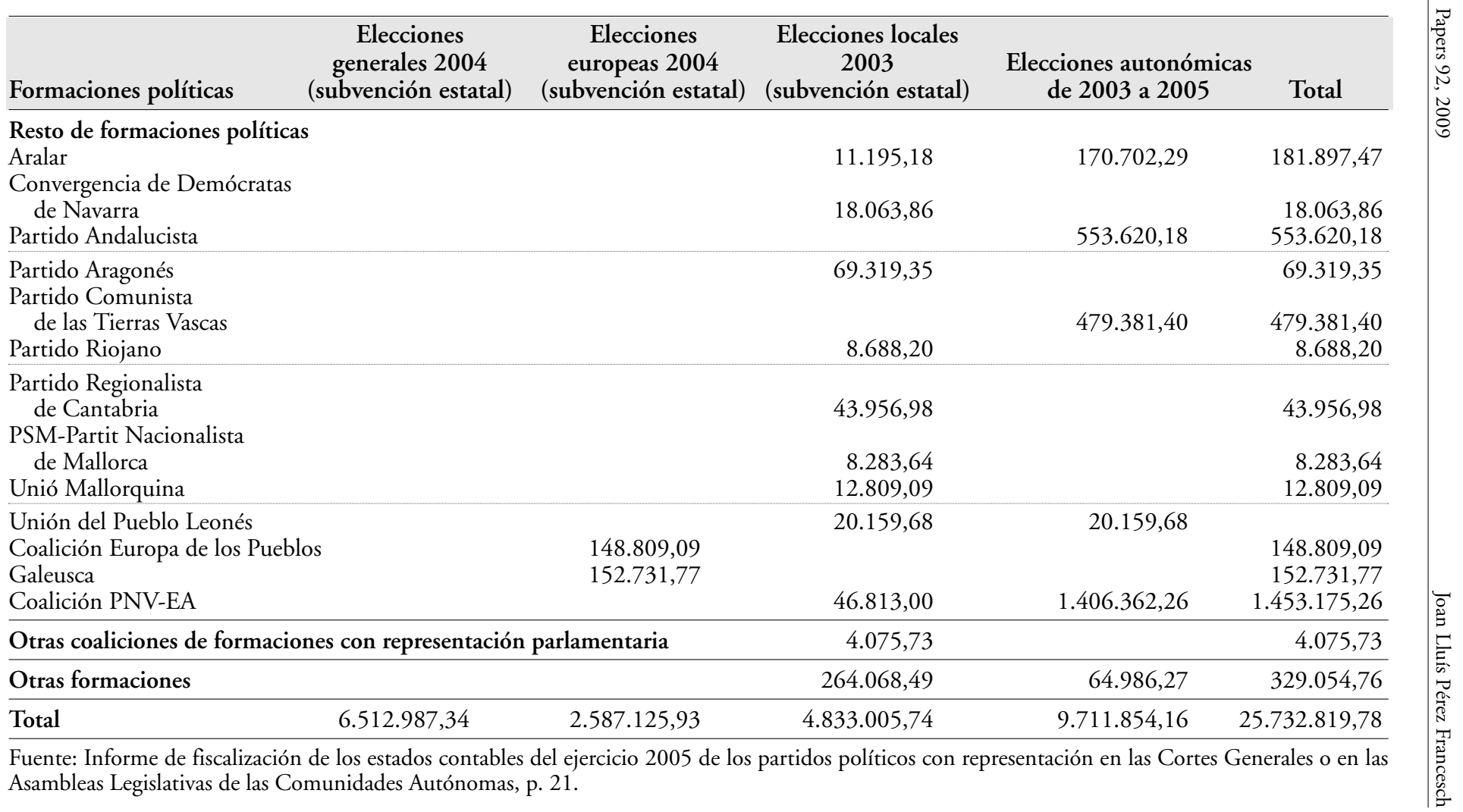


Anexo 6. Subvenciones electorales recibidas por los partidos políticos con representación parlamentaria en el Congreso de los Diputados, con ocasión del referéndum celebrado el 20 de febrero de 2005 (proyecto de tratado por el que se instituye una constitución para Europa)

\section{Formaciones políticas}

Bloque Nacionalista Galego

Coalición Canaria

Chunta Aragonesista

Federación Convergència i Unió

Eusko Alkartasuna

Esquerra Republicana de Catalunya

Iniciativa per Catalunya Verds

Izquierda Unida

Partido Nacionalista Vasco

Partido Popular

Partit dels Socialistes de Catalunya

Partido Socialista Obrero Español

Unión del Pueblo Navarro
Importe (en euros)

68.104,47

$83.155,25$

$31.587,77$

$289.736,30$

$28.328,43$

$224.591,29$

$72.791,16$

$263.164,84$

$162.160,51$

3.427.196,51

567.483 .85

$3.530 .819,34$

$44.721,09$

Fuente: Informe de fiscalización de los estados contables del ejercicio 2005 de los partidos políticos con representación en las Cortes Generales o en las Asambleas Legislativas de las Comunidades Autónomas, p. 22. 